vessel, bronchus, or interlobar space. When a silicone tube guide is used, the vessel, bronchus, or lung tissue is stapled while keeping the guide attached (Figure 2). When the Penrose drain is used, we remove the drain from the tip of the endostapler and then staple the tissue.

\section{Results}

There was no misfire or accidental injury of vessels or surrounding tissues in the use of the endostapler. The time between dissecting the vessels and the end of stapling with the silicone tube guide was significantly shorter than that with the Penrose drain (mean $\pm \mathrm{SE}$ : silicone tube, $191 \pm 25$ seconds; Penrose drain, $392 \pm 94$ seconds; $P<.01)$.

\section{Discussion}

Mechanical stapling for vessels and bronchus is a safe method, especially in video-assisted thoracoscopic lung lobectomy. A Penrose drain has been used as a guide for the endostapler. However, it must be detached from the jaw of the endostapler before stapling near the hilum of the lung in the thoracic cavity. The elasticity of the Penrose drain is so soft that it occasionally fails to lead the endostapler behind the vessel.
The silicone tube guide is so small that we can pass the $11-\mathrm{mm}$ port as it is attached to the jaw, and therefore the attachment on the jaw can be made out of the body. In addition, an endostapler can be attached to either side of the silicone guide. It has elasticity appropriate for guiding the tip of the endostapler. The biggest advantage of this guide is that stapling can be done with the guide attached. We can control the position of the tip of the endostapler at the time of stapling with the silicone tube. It simplifies intrathoracic manipulation and eliminates the possibility of injuring other vessels or lung tissue with the jaw. It also saves operating time.

\section{Conclusions}

The use of a soft silicone tube guide can improve the safety of lung lobectomy with automatic suture devices and shorten the operative time.

\section{References}

1. Szwerc MF, Landreneau RJ, Santos RS, Keenan RJ, Murray GF. Minithoracotomy combined with mechanically stapled bronchial and vascular ligation for anatomical lung resection. Ann Thorac Surg. 2004; 77:1904-9.

2. Abramson DJ. Charles Bingham Penrose and the Penrose drain. Surg Gynecol Obstet. 1976;143:285-6.

\title{
Mitral valve reconstruction in a compound heterozygote for sickle cell anemia and hemoglobin Lepore
}

Konstantinos Tziomalos, MD, ${ }^{a}$ Vassilia Garipidou, MD, ${ }^{\text {a }}$ Eleni Houmpouridou, MD, ${ }^{\mathrm{b}}$ Antonios A. Pitsis, MD, ${ }^{c}$ and Elias Basayannis, MD, ${ }^{a}$ Thessaloniki, Greece

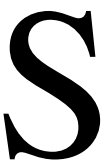

ickle cell disease presents a multitude of challenges in patients undergoing cardiac operations. In these patients, cardiopulmonary bypass (CPB) may trigger a crisis of profound magnitude. The prevention of sickling of red blood cells and its sequelae of hemolysis and

\footnotetext{
From the Second Propaedeutic Department of Internal Medicine, Aristotle University of Thessaloniki, Hippokration Hospital, ${ }^{\mathrm{a}}$ and the Department of Hematology ${ }^{\mathrm{b}}$ and the Thessaloniki Heart Institute, ${ }^{\mathrm{c}}$ St Luke's Hospital, Thessaloniki, Greece,

Received for publication Jan 23, 2005; accepted for publication Feb 22, 2005.

Address for reprints: Konstantinos Tziomalos, MD, 63 Solonos St, Thessaloniki, 54248 Greece (E-mail: ktziomalos@yahoo.com).

J Thorac Cardiovasc Surg 2005;130:932-3

$0022-5223 / \$ 30.00$

Copyright $\odot 2005$ by The American Association for Thoracic Surgery

doi:10.1016/j.jtcvs.2005.02.037
}

vaso-occlusive crises during $\mathrm{CPB}$ is achieved primarily by reducing the level of

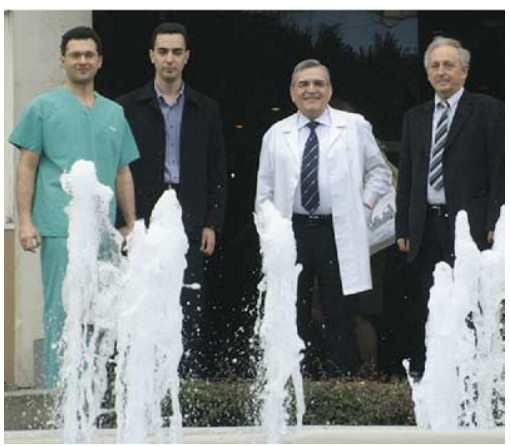

Pitsis, Tziomalos, Katsarkas, Basayannis (left to right) hemoglobin $\mathrm{S}$ before operation. $^{1,2}$

Hemoglobin Lepore $(\alpha 2[\delta \beta] 2)$ is a hemoglobin variant with a $\delta \beta$ chain that is a result of fusion of a $\delta$ and a $\beta$ globin gene. The hybrid gene is expressed at a roughly intermediate level, between the $\delta$ and the $\beta$ globin genes. The phenotype of the heterozygote thus closely resembles the classical thalassemia trait. To date, only 20 cases of compound heterozygotes with hemoglobin Lepore/hemoglobin S have been reported, and they are characterized by hematologic as well as clinical heterogeneity. The hemoglobin S/hemoglobin Lepore combination may have enough hemoglobin $\mathrm{S}$ to cause serious sickling, particularly if an excess of $\delta$ chains were to have harmful consequences, as has been asserted. ${ }^{3}$ We report a case of mitral valve reconstruction performed safely in a compound heterozygote for sickle cell anemia and hemoglobin Lepore. 


\section{Clinical Summary}

A 26-year-old Greek man, compound heterozygote for sickle cell anemia and hemoglobin Lepore, came to our department with symptoms of progressive dyspnea and fatigue. His medical history was significant for several hospital admissions for sickling crises, one of which had necessitated blood transfusions.

On physical examination, the patient had a blood pressure of $100 / 70 \mathrm{~mm} \mathrm{Hg}$, a pulse of 90 beats/min, and a respiratory rate of 16 breaths/min. The heart had a regular rhythm, with a 3/6 apical holosystolic murmur radiating to the axilla. Further evaluation, including transesophageal echocardiography, disclosed severe mitral regurgitation, with prolapse of the anterior mitral valve leaflet, accompanied by annular dilatation and significant left atrial and left ventricular enlargement. Left ventricular internal dimensions during diastole and systole were $68 \mathrm{~mm}$ and $54 \mathrm{~mm}$, respectively. Catheterization demonstrated a pulmonary artery pressure of 45/21 $\mathrm{mm} \mathrm{Hg}$ and a left ventricular end-diastolic pressure of $22 \mathrm{~mm} \mathrm{Hg}$. The ventriculogram noted global hypokinesis, with an ejection fraction of 0.43 . Coronary angiography showed no abnormalities. The patient was referred for mitral valve repair.

Approximately 1 week before the operation, the patient underwent therapeutic phlebotomy and exchange transfusion with leukocyte-depleted, phenotypically matched packed erythrocytes to decrease the level of hemoglobin S. Hemoglobin and hematocrit at that time were $10.2 \mathrm{~g} / \mathrm{dL}$ and $33.2 \%$, respectively. Hemoglobin electrophoresis demonstrated $77.5 \%$ hemoglobin S. After the exchange transfusion, hemoglobin and hematocrit remained stable, but hemoglobin S was only $44.5 \%$.

The procedure was carried out with normothermic $\left(37^{\circ} \mathrm{C}\right) \mathrm{CPB}$. After crossclamping of the aorta, intermittent, antegrade, hyperkalemic warm blood cardioplegia supplemented with magnesium was administered in the aortic root. ${ }^{4}$ The mitral valve was approached through the superior septal approach. It was found to be a Barlow type of valve, with annular dilatation and excess tissue in both mitral leaflets. It was repaired with a flexible mitral ring (size 36 mm Annuloflex; Sulzer Carbomedics Inc, Austin, Tex). Aortic crossclamp time was 32 minutes. Intraoperative transesophageal echocardiography showed no residual mitral regurgitation.

The patient had an uneventful postoperative recovery. He was discharged from the hospital on the sixth postoperative day.

\section{Discussion}

The absolute safe level of hemoglobin $\mathrm{S}$ during operations with CPB has not been clearly defined. A growing body of evidence suggests that limited dilution of sickle cells is beneficial. In a pivotal study, a preoperative hemoglobin S level of $30 \%$ or less allowed elective surgery to be performed safely in patients with sickle cell disease; these values may represent a suitable aim for patients undergoing $\mathrm{CPB} .^{5}$ Hemoglobin $\mathrm{S}$ reduction can be achieved by simple transfusion for several weeks preoperatively, partial exchange transfusion in the preoperative period, complete exchange transfusion with the CPB circuit, or a combination of these techniques. ${ }^{1,2}$ Preoperative exchange transfusion increases the percentage of hemoglobin A relative to that of hemoglobin $\mathrm{S}$ and, more importantly, suppresses further production of hemoglobin S.

During an operation, predisposing factors that elicit sickling (including hypoxia, low-flow states, hypovolemia, acidosis and hypothermia) should be avoided. ${ }^{1,2}$ Hypothermia can cause vasoconstriction and slugging of red cells and therefore potentially increase capillary transit time and the risk of sickling of red cells. In view of this potential complication of hypothermia, we aimed to perform warm heart surgery with normothermic CPB of the minimum duration.

In conclusion, preoperative exchange transfusion enabled us to perform mitral valve repair uneventfully in a compound heterozygote for sickle cell anemia and hemoglobin Lepore.

\section{References}

1. Chun PKC, Flannery EP, Bowen TE. Open-heart surgery in patients with hematologic disorders. Am Heart J. 1983;105:835-42.

2. Metras D, Coulibaly AO, Ouattara K. Open heart surgery in sickle cell hemoglobinopathies: report of 15 cases. Thorax. 1982;37:486-91.

3. Seward DP, Ware RE, Kinney TR. Hemoglobin sickle-Lepore: report of two siblings and review of the literature. Am J Hematol. 1993; 44:192-5.

4. Caputo M, Bryan AJ, Calafiore AM, Suleiman MS, Angelini GD. Intermittent antegrade hyperkalaemic warm blood cardioplegia supplemented with magnesium prevents myocardial substrate derangement in patients undergoing coronary artery bypass surgery. Eur J Cardiothorac Surg. 1998;14:596-601.

5. Vichinsky EP, Haberkern CM, Neumayr L, Earles AN, Black D, Koshy $\mathrm{M}$, et al. A comparison of conservative and aggressive transfusion regimens in the perioperative management of sickle cell disease. The Preoperative Transfusion in Sickle Cell Disease Study Group. N Engl J Med. 1995;333:206-13. 